\title{
Influence of Sub- Versus Top-irrigation and Surfactants in a Recirculating System on Disease Incidence Caused by Phytophthora spp. in Potted Pepper Plants
}

\author{
M. E. Stanghellini, C. J. Nielsen, and D. H. Kim, Department of Plant Pathology, University of California, River- \\ side 92521; and S. L. Rasmussen and P. A. Rorbaugh, Department of Plant Pathology, University of Arizona, \\ Tucson 85721
}

\begin{abstract}
Stanghellini, M. E., Nielsen, C. J., Kim, D. H., Rasmussen, S. L., and Rorbaugh, P. A. 2000. Influence of sub- versus top-irrigation and surfactants in a recirculating system on disease incidence caused by Phytophthora spp. in potted pepper plants. Plant Dis. 84:1147-1150.

Zoospores of Phytophthora capsici spread from inoculated source plants to healthy potted pepper plants located on separate ebb-and-flow benches when the recycled nutrient solution originated from a common reservoir. Amending the recirculating nutrient solution with a surfactant, which selectively kills zoospores, resulted in $100 \%$ control of the spread of the pathogen in an ebb-and-flow and a top-irrigated cultural system. Without a surfactant in the recirculating nutrient solution, all plants in an ebb-and-flow cultural system died within 6 weeks. In contrast, all plants in a top-irrigated cultural system died within 2 weeks after inoculation of source plants. These results suggest that the use of recycled irrigation water in an ebb-and-flow cultural system is less conducive to pathogen spread than its use in a top-irrigated cultural system, but may still serve as efficient means of inoculum movement in the absence of control measures.
\end{abstract}

Growers of potted greenhouse crops face strict governmental regulations concerning discharge of spent nutrient solutions because of possible groundwater pollution resulting from the nutrient salts and agricultural chemicals present. A result of these regulations is the increased use of recaptured and recycled irrigation water in the greenhouse and outdoor nursery production industries. Although recycling of the nutrient solution will decrease pollution, serious grower concerns exist regarding the spread of root-infecting pathogens, particularly in ebb-and-flow cultural systems. It is well known that recirculation of pathogen-infested nutrient solution contributes significantly to the spread of zoosporic pathogens (i.e., Pythium and Phytophthora spp.) in hydroponically grown vegetable crops in soilless cultural systems (3). Although it has been documented that zoosporic pathogens can spread from infected to healthy potted plants located on the same ebb-and-flow bench $(1,5,6)$, it has not been established whether these pathogens can spread from an infested bench to other benches serviced by a common nutrient solution reservoir.

Corresponding author: M. E. Stanghellini

E-mail: michael.stanghellini@ucr.edu

This work was supported in part by the American Floral Endowment.

Accepted for publication 10 July 2000.

Publication no. D-2000-0821-01R

(C) 2000 The American Phytopathological Society
Pathogen control remains problematic in cultural systems employing recycled nutrient solutions. The efficacy of surfactants in the control of certain zoosporic pathogens (e.g., Pythium aphanidermatum (Edson) Fitzp. and Phytophthora capsici Leonian) in vegetable crops cultivated hydroponically in an inorganic substrate has been documented $(2,4)$. However, the efficacy of surfactants in the control of diseases caused by zoosporic pathogens in cultural systems in which plants are cultivated in an organic substrate (i.e., potting medium) has not been demonstrated.

Our specific objectives were to (i) assess the ability of a zoosporic pathogen to spread in an ebb-and-flow cultural system from infested pots on one bench to healthy plants on a different bench solely via the recirculating nutrient solution, (ii) evaluate the efficacy of surfactants in the control of root disease caused by a zoosporic pathogen in recirculating systems in which plants are cultivated in an organic substrate, and (iii) assess the relative dangers of pathogen spread in an ebb-and-flow cultural system versus a top-irrigated sys- tem employing a recycled nutrient solution.

\section{MATERIALS AND METHODS}

Pathogen and host. All experiments were conducted using pepper (Capsicum annuum L. cv. Joe Parker) as the susceptible host and Phytophthora capsici Leonian as the root pathogen. Stock cultures of the pathogen were stored in sterile distilled water, and working cultures were grown on $10 \%$ V8 agar medium.

Ebb-and-flow cultural system. Unless otherwise specified, all experiments were conducted in a temperature-controlled greenhouse $\left(24\right.$ to $\left.32^{\circ} \mathrm{C}\right)$ containing 12 two-sided ebb-and-flow units. Each unit (Fig. 1) consisted of two troughs (each 133 $\mathrm{cm}$ in length by $15 \mathrm{~cm}$ in width) that were connected to a common 50-liter reservoir.

Pepper seedlings (35 days old) grown in Oasis blocks (Smithers-Oasis, Kent, $\mathrm{OH}$ ) in a temperature-controlled incubator were transplanted into 9-cm-diameter pots containing a commercial organic (peat-based), potting medium (PRO-MIX, Premier Horticulture, Inc., Red Hill, PA). Potted plants were then placed in ebb-and-flow troughs and grown for another 3 weeks before inoculation. There were 8 potted plants per trough, 16 plants per unit. Each unit was subirrigated daily for 1 to $2 \mathrm{~h}$. The depth of the nutrient solution in the troughs ranged from 3 to $5 \mathrm{~cm}$. After irrigation, the nutrient solution was allowed to drain by gravity back into the reservoir. The nutrient solution composition, electrical conductivity, and $\mathrm{pH}$ were monitored and maintained as previously reported (4).

There were two separate experiments. Each experiment consisted of four treatments with three replications per treatment. Treatments included noninoculated units, inoculated units, inoculated units in which the nutrient solution was amended with a

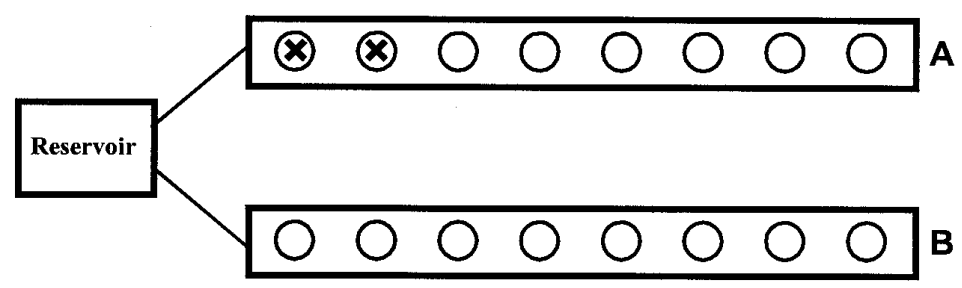

Fig. 1. Schematic of an ebb-and-flow cultural system employed to evaluate the spread and control of Phytophthora capsici in recycled irrigation water. There were eight potted pepper plants on each side of the cultural system. Two plants (X) were inoculated with the pathogen. 
surfactant, and noninoculated units in which the nutrient solution was amended with a surfactant.

Inoculation was conducted when the plants were 56 days old, as follows: a 5mm-diameter disk cut from the advancing margin of a 5-day-old culture of the pathogen was placed in contact with the lower hypocotyl of two consecutive plants on one side (side A) of an ebb-and-flow unit (Fig. 1). One plant was inoculated on day 1 and a second plant was inoculated on day 7 . This method of inoculation permitted us to evaluate pathogen spread within an ebband-flow unit following colonization and natural reproduction on the roots of the inoculated plants. The sequential inoculation of two plants was conducted because preliminary studies showed that if the first inoculated plant died too rapidly, little secondary inoculum was produced for pathogen spread. Therefore, we inoculated a second plant (which was now 1 week older and had a larger root system for pathogen reproduction). Irrespective of plant age at the time of inoculation, inoculated plants wilted and died within 7 days after inoculation.

In addition to the ebb-and-flow (i.e., subirrigation) experiments, we conducted pot experiments in which the recirculating nutrient solution was delivered to the plants for 30 min every $3 \mathrm{~h}$ via emitters (7.5 liters/h). Emitters were positioned 2 $\mathrm{cm}$ above the surface of the potting medium (i.e., top-irrigation system) and approximately $1 \mathrm{~cm}$ in horizontal distance from the hypocotyl of the pepper plant. In the top-irrigated system (Fig. 2), potted pepper plants were located in a single trough (five plants per trough). Treatments were the same as those used in the subirrigation study, except that only one potted plant was inoculated per trough. Plants were 41 days old at time of inoculation. All treatments were replicated twice and the experiment was repeated once.

Surfactants. Two synthetic surfactants (Aquagro 2000L, Aquatrols, Cherry Hills, NJ; and Naiad Soil Penetrant, Naiad Company, Pleasanton, CA) were used. Aquagro 2000L was used in the first ebb-and-flow experiment but was not commercially available for further studies. Thus, Naiad was used in all subsequent experiments. In vitro studies showed that both of these surfactants were equally efficacious in lysing zoospores. In the subirrigation experiments, surfactants were added to the reservoir of recirculating systems at the following rates: $200 \mu \mathrm{g}$ a.i./ml 1 week prior to inoculation and then $100 \mu \mathrm{g}$ a.i./ml at 7 to 14-day intervals. Reapplication was based upon visual disappearance of foaming in the reservoir. In the top-irrigation experiments, surfactants had to be reapplied at 3- to 7-day intervals to maintain visual evidence of foaming in the reservoirs.

Monitoring zoospore presence in the recirculating nutrient solution and in leaves was used to detect zoospores in the nutrient solution from surfactant-amended and nonsurfactant-amended units. Unless otherwise specified, all studies involving detection of zoospores in the recirculating nutrient solution were conducted during the fourth and fifth week of each experiment. Twenty $10-\mathrm{ml}$ samples of the nutrient solution (at 0 to $5 \mathrm{~cm}$ of depth) were collected in small petri dishes $(5.6 \mathrm{~cm}$ in diameter) from the reservoirs of all treatments immediately prior to and at various time intervals after an irrigation cycle, and from the trough containing the potted plants during the stationary phase of an irrigation cycle. Additionally, the rapidity at which zoospores could be detected inside a pot containing an infected plant was determined as follows: a perforated plastic centrifuge tube (measuring $7.5 \mathrm{~cm}$ in length and $1.6 \mathrm{~cm}$ in diameter) was inserted into the potting soil approximately 2 $\mathrm{cm}$ from the hypocotyl of an infected pepper plant (Fig. 3). At 15-min intervals over a 120-min time period after commencement of subirrigation, the nutrient solution, which percolated into the centrifuge tube, was withdrawn from the tube via a syringe and dispensed into small petri dishes. soil. A baiting technique employing pepper

Samples of the nutrient solution, obtained from the various locations listed above, were then transported to the laboratory where a $0.5-\mathrm{cm}^{2}$ piece of freshly cut pepper leaf was floated on the surface of each sample. After $72 \mathrm{~h}$ of incubation at $24^{\circ} \mathrm{C}$, the leaf was examined microscopically at magnification $\times 4$ to $\times 20$ for sporulation (sporangia formation) of $P$. capsici around the perimeter of the leaf bait. The percentage of leaf baits colonized per treatment was recorded. All baiting studies were replicated at least twice in each of the two experiments. In addition to monitoring the zoospore population in the recirculating nutrient solution, mortality of plants in each treatment was recorded daily throughout the duration of each experiment. At the termination of each experiment, five root segments, each 1 to $2 \mathrm{~cm}$ long, were excised from three plants from each treatment and plated on water agar medium. After $72 \mathrm{~h}$ of incubation at $24^{\circ} \mathrm{C}$, hyphae emerging from the roots were transferred to V8 agar medium and the cultures were identified.

\section{RESULTS}

Mortality of pepper plants in subirrigated (ebb-and-flow) experiments. In the

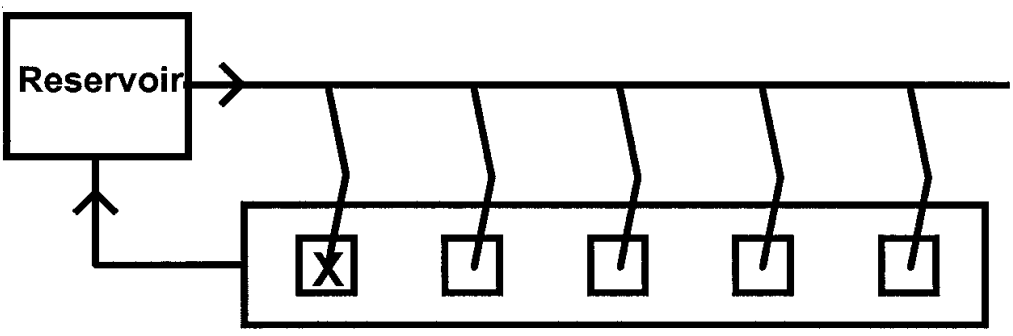

Fig. 2. Schematic of a top-irrigated cultural system employed to evaluate the spread and control of Phytophthora capsici in recycled irrigation water. There were five potted pepper plants in the cultural system. One plant $(\mathrm{X})$ was inoculated with the pathogen.

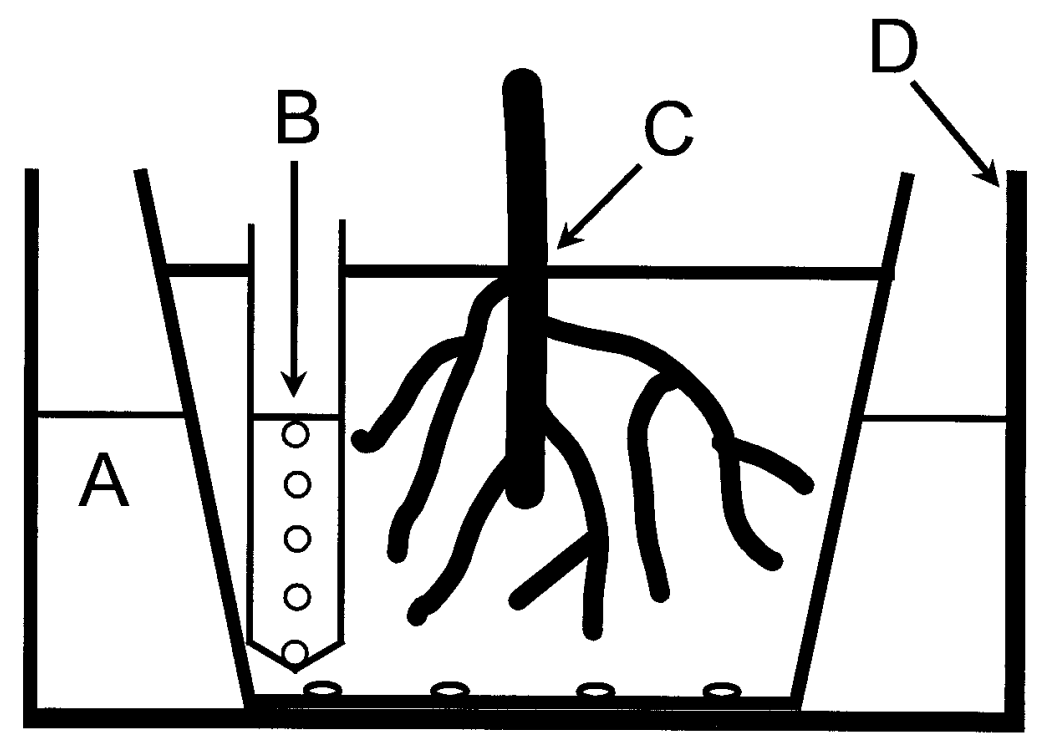

Fig. 3. Cross section of a schematic illustrating the nutrient solution collection sites outside (A) and inside (B) a pot containing a Phytophthora capsici infected pepper plant (C) located in an ebb-andflow cultural unit (D). 
absence of a surfactant, the two inoculated plants located on side A of an ebb-andflow unit died within 1 week after inoculation and all the noninoculated plants on side A died by week 6 . Mortality of pepper plants on the noninoculated side of a unit (side B) was first observed 5 weeks after inoculation of plants on side $\mathrm{A}$ and all plants on side B died within the next week (week 6 after inoculation of plants on side A). In contrast, only inoculated plants died in the surfactant-amended treatments located on side A of the subirrigated ebband-flow units (Fig. 4, Table 1). The experiment was repeated with similar results.

No mortality of pepper plants occurred in any of the noninoculated or noninoculated plus surfactant-amended treatments. Additionally, $P$. capsici was isolated from the roots of all dead plants from nonsurfactant-amended inoculated units but not from any of the roots of plants from the noninoculated or surfactant-amended treatments.

Mortality of pepper plants in top-irrigated (drip) experiments. In the absence of a surfactant, all inoculated plants in top- irrigated units died within $48 \mathrm{~h}$ after inoculation and the remaining four plants in each unit died within the next 12 days. In contrast, the only plants that died in the surfactant-amended treatments were the inoculated plants (Table 2).

Pathogen detection in the recirculating nutrient solution and in soil. Colonization of pepper leaf baits by $P$. capsici occurred only in samples of the nutrient solution that were obtained from inoculated treatments that were not amended with a surfactant (Fig. 5). A low but detectable population of motile zoospores was present in the nutrient solution immediately prior to irrigation. Within $15 \mathrm{~min}$ after commencement of an irrigation cycle, motile zoospores were detected inside pots containing an infected plant. Sixty min after commencement of an irrigation cycle, zoospores were consistently detected in the nutrient solution outside the pot in the trough. Following the return of the solution to the reservoir after an irrigation cycle, the motile zoospore population in the reservoir increased dramatically within a short time and then gradually declined over time.

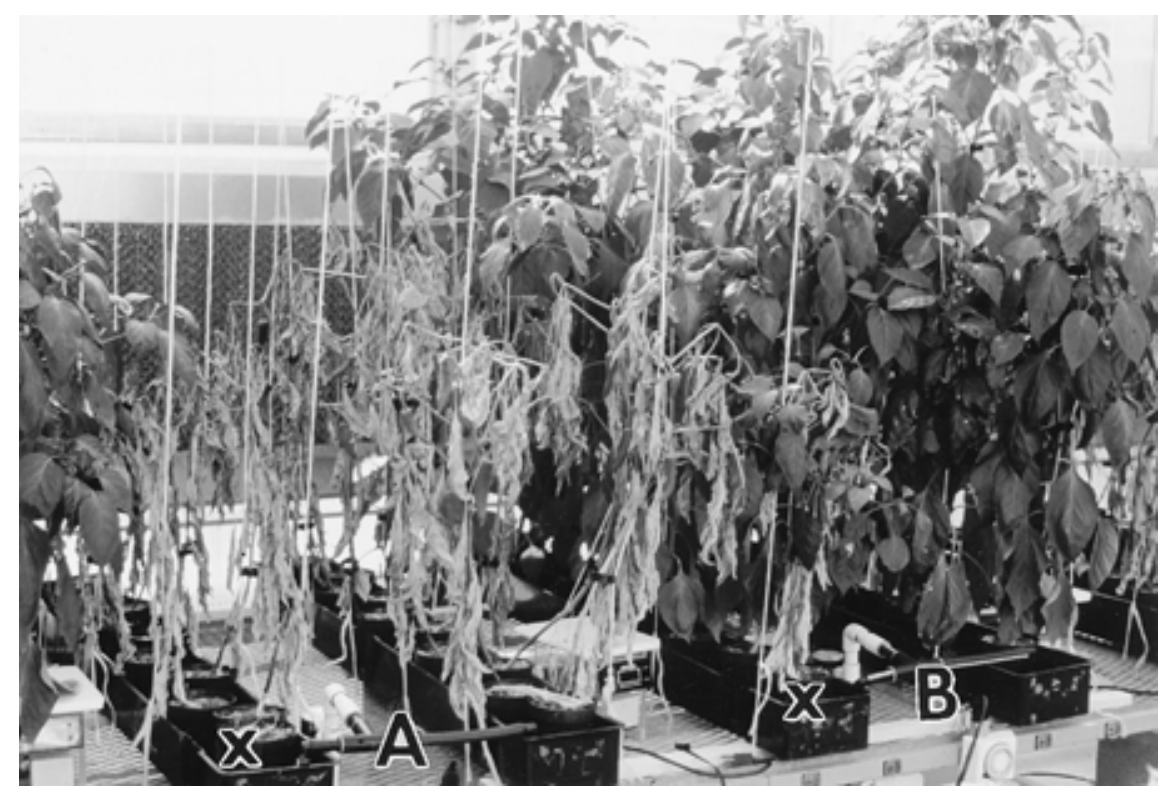

Fig. 4. Mortality of pepper plants on the inoculated and noninoculated side of a two-sided ebb-andflow cultural system in the (A) absence or (B) presence of a surfactant in the recirculating nutrient solution. $\mathrm{X}=$ the inoculated plants that served as the source of secondary inoculum.

\section{DISCUSSION}

The potential for spread of root-infecting pathogens in recycled irrigation water is of major concern to greenhouse growers. Previous studies in ebb-and-flow systems demonstrated that pathogen spread can occur from an inoculated "source plant" to healthy plants located on the same ebband-flow bench and that spread was associated with an irrigation $(1,5,6)$. However, it was not established whether pathogen spread was associated with the recycled nutrient solution. The respective zoosporic pathogens used in these latter studies were seldom $(5,6)$ or never (1) recovered from the recirculated nutrient solution in the reservoir. Additionally, disease incidence was usually highest in those plants nearest the source plants $(5,6)$. The latter pattern of spread suggested that the primary source of inoculum was the infected plants on the bench. If the recycled nutrient solution from the reservoir was the primary source of inoculum, a more uniform distribution of infected plants on a bench would have been observed.

The results of our investigation provide evidence that pathogen populations that survive in recycled irrigation water between irrigation cycles can function as a source of inoculum for pathogen spread. There was a high incidence of disease in plants (100\% mortality) on an ebb-andflow bench irrigated with recycled nutrient solution from a reservoir that was used to irrigate a separate ebb-and-flow bench containing diseased plants. The absence of disease in noninoculated ebb-and-flow units demonstrated that the inoculated source plants provided the secondary inoculum for pathogen infestation of the recycled irrigation water. Additionally, lack of disease spread in inoculated but surfactant-amended ebb-and-flow units conclusively demonstrated that zoospores, which are selectively killed by surfactants, $(2,4)$ were the primary infectious propagule of the pathogen associated with infestation of the nutrient solution. Within 15 min after commencement of an irrigation, zoospores were formed inside pots of inoculated plants and, after $60 \mathrm{~min}$, they were detected in the nutrient solution outside the pots. At the end of an irrigation

Table 1. Percent mortality of pepper plants after hypocotyl inoculation of two plants on one side (side A) of a two-sided ebb-and-flow subirrigation cultural unit with Phytophthora capsici

\begin{tabular}{|c|c|c|c|c|c|c|c|c|c|}
\hline \multirow[b]{2}{*}{ Treatments $^{b}$} & \multirow[b]{2}{*}{ Side } & \multicolumn{8}{|c|}{ Weeks after inoculation $^{\mathrm{a}}$} \\
\hline & & 1 & 2 & 3 & 4 & 5 & 6 & 7 & 8 \\
\hline \multirow{2}{*}{ Check } & A & 0 & 0 & 0 & 0 & 0 & 0 & 0 & 0 \\
\hline & B & 0 & 0 & 0 & 0 & 0 & 0 & 0 & 0 \\
\hline \multirow[t]{2}{*}{ Surfactant } & A & 0 & 0 & 0 & 0 & 0 & 0 & 0 & 0 \\
\hline & B & 0 & 0 & 0 & 0 & 0 & 0 & 0 & 0 \\
\hline \multirow[t]{2}{*}{ P. capsici + surfactant } & A & 12.5 & 12.5 & 25 & 25 & 25 & 25 & 25 & 25 \\
\hline & B & 0 & 0 & 0 & 0 & 0 & 0 & 0 & 0 \\
\hline \multirow[t]{2}{*}{ P. capsici } & A & 12.5 & 12.5 & 25 & 41.6 & 70.8 & 100 & $\ldots$ & $\ldots$ \\
\hline & B & 0 & 0 & 0 & 0 & 20.8 & 100 & $\ldots$ & $\ldots$ \\
\hline
\end{tabular}

\footnotetext{
a Pepper seedlings were 56 days old at time of inoculation. There were eight plants on side A and eight plants on side B of each unit.
}

b Mean percent mortality from three replications per treatment. 
Table 2. Percent mortality of pepper plants after hypocotyl inoculation of one plant in a recirculating top-irrigated cultural unit with Phytophthora capsici

\begin{tabular}{lrrr}
\hline & \multicolumn{3}{c}{ Weeks after inoculation $^{\mathbf{a}}$} \\
\cline { 2 - 4 } Treatments $^{\mathbf{b}}$ & $\mathbf{1}$ & $\mathbf{2}$ & $\mathbf{3}$ \\
\hline Check $_{\text {Surfactant }}$ & 0 & 0 & 0 \\
$P$. capsici + surfactant & 0 & 0 & 0 \\
$P$. capsici & 20 & 20 & 20 \\
\end{tabular}

a Pepper seedlings were 41 days old at time of inoculation. There were five plants per unit.

b Mean percent mortality from two replications. The experiment was repeated with similar results.

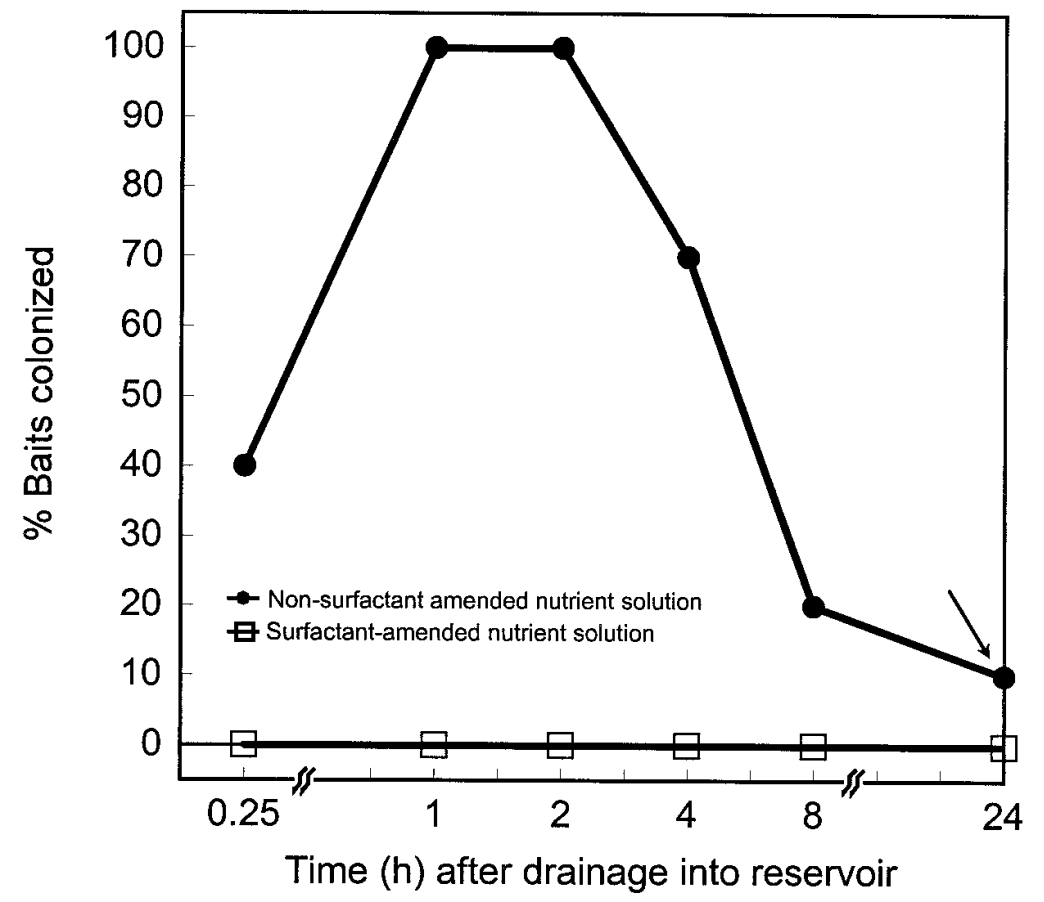

Fig. 5. Percentage of pepper leaf baits colonized by zoospores of Phytophthora capsici immediately prior to an irrigation cycle (arrow) and at various time intervals after the return of the nutrient solution to the reservoir following an irrigation cycle. Twenty 10-ml samples of the nutrient solution were collected at each time interval indicated. Data are from one inoculated, nonsurfactant-amended and one inoculated, surfactant-amended ebb-and-flow cultural unit. The data presented are representative of results from replicated treatments from each of two separate experiments.

cycle, the nutrient solution was allowed to drain back into the reservoir by gravity. High populations of motile zoospores, as evidenced by the high percentage leaf baits colonized, were detected in the reservoir for several hours. The zoospore population in the reservoir then progressively declined over time but was still detectable by the leaf bait technique immediately prior to the next irrigation cycle (i.e., $24 \mathrm{~h}$ later). The population of motile zoospores, plus the possibility of more numerous but undetected encysted zoospores, were obviously capable of functioning as secondary inoculum for spread via the recycled nutrient solution in an ebb-and-flow subirrigation system.
In addition to grower concerns regarding the possibility of pathogen spread in an ebb-and-flow cultural system, questions have been raised by growers regarding the relative danger of pathogen spread in an ebb-and-flow system of irrigation compared to other types of irrigation systems (e.g., top-irrigation). Our results indicate that an ebb-and-flow cultural system is less conducive to pathogen spread than a topirrigated cultural system. Mortality rates of pepper plants due to $P$. capsici were much slower in an ebb-and-flow system compared with a top-irrigated system. Interestingly, the rapid plant mortality rates in the top-irrigated, potted plant studies re- ported herein were identical to those recorded in our previous studies involving top-irrigation in a soilless rockwool system (2). The rapidity of plant death in top-irrigated systems was not related to plant age at the time of inoculation. For example, in our studies conducted in a top-irrigated rockwool system, plants ranged from 47 to 75 days old at the time of inoculation and all plants within the system died within 2 weeks after inoculation. We attribute the more rapid rate of plant mortality in topirrigated systems to (i) a greater number of daily irrigations that increases the probability of pathogen introduction and (ii) a higher probability of chance encounter between propagules of the pathogen and the roots of the susceptible plants because all incoming irrigation water in a top-irrigated system drains through the entire volume of the substrate in a pot.

One of the objectives of our investigation was to evaluate the efficacy of surfactants in the control of root disease caused by a zoosporic pathogen in recirculating irrigation systems in which plants are cultivated in an organic substrate. Our results conclusively demonstrated that surfactants provide excellent $(100 \%)$ control of root rot of pepper caused by $P$. capsici, a zoosporic pathogen, in both top- and subirrigation type systems in plants grown in an organic substrate. These results confirm and extend our previous findings conducted in soilless cultural systems $(2,4)$.

\section{LITERATURE CITED}

1. Sanogo, S., and Moorman, G. W. 1993. Transmission and control of Pythium aphanidermatum in an ebb-and-flow subirrigation system. Plant Dis. 77:287-290.

2. Stanghellini, M. E., Kim, D. H., Rasmussen, S. L., and Rorabaugh, P. A. 1996. Control of root rot of peppers caused by Phytophthora capsici with a nonionic surfactant. Plant Dis. 80:11131116.

3. Stanghellini, M. E., and Rasmussen, S. L. 1994. Hydroponics: A solution for zoosporic pathogens. Plant Dis. 78:1129-1138.

4. Stanghellini, M. E., Rasmussen, S. L., Kim, D. H., and Rorabaugh, P.A. 1996. Efficacy of nonionic surfactants in the control of zoospore spread of Pythium aphanidermatum in a recirculating hydroponic system. Plant Dis. 80:422428.

5. Strong, S. S., Behe, B. K., Deneke, C. F., Bowen, K. L., and Keever, G. J. 1997. Cultivar and spacing effects on transmission of Phytophthora parasitica in an ebb-and-flow subirrigation system. Plant Dis. 81:89-95.

6. Thinggaard, K., and Anderson, J. 1995. Influence of watering frequency and electrical conductivity of the nutrient solution on Phytophthora root rot in pot plants of Gerbera. Plant Dis. 79:259-263. 